\title{
Grupos domésticos y migración masculina. Estudio de caso en Godoy, municipio de Salamanca, Guanajuato
} Azucena Isabel Flores López*, Andrés Pérez Magaña**, Beatriz Martínez Corona***, Jesús Soriano Fonseca****

\section{Resumen}

El artículo que aquí se presenta centra su análisis en las temáticas de la migración masculina y los grupos domésticos rurales. El objetivo es identificar de qué manera la migración masculina afecta la dinámica cotidiana de los grupos domésticos de una comunidad rural del municipio de Salamanca, Guanajuato. Se pone énfasis especial en las repercusiones que trae consigo la migración para las madres y esposas de los migrantes. Para obtener la información de campo se utilizaron las siguientes herramientas: la encuesta y la entrevista semiestructurada. Entre los principales resultados se encontró que la migración obliga a los grupos domésticos a redistribuir sus actividades, siendo las esposas de los migrantes las que principalmente aumentan su carga de trabajo y responsabilidades, lo cual no sucede con las madres.

\section{Abstract}

The article presented here focuses its analysis on the issues of male migration and rural domestic groups. The objective is to identify ways in which male migration affects the dynamics of everyday domestic groups in a rural community in the municipality of Salamanca, Guanajuato. It puts special emphasis on the impact of migration for the mothers and wives of migrants. For field data were used the following tools: the survey and semi-structured interview. The main results found that migration requires domestic groups to redistribute their activities, being the wives of migrants who mainly increase their workload and responsibilities, which does not happen with mothers.

Keywords: male migration, domestic groups, redistribution of activities.

Palabras clave: migración masculina, grupos domésticos, redistribución de actividades.

* Maestra en Ciencias, Colegio de Postgraduados campus Puebla. Correo electrónico: isabel_floreslopez@yahoo.com.mx.

** Doctor, Colegio de Postgraduados campus Puebla. Correo Electrónico: apema@colpos.mx.

*** Doctora, Colegio de Postgraduados campus Puebla. Correo Electrónico: bethmac3@yahoo.com.

****** Doctor, Universidad Autónoma Chapingo. Correo electrónico: jesussoriano51@ gmail.com. 


\section{Introducción}

La migración internacional es un fenómeno histórico en nuestro país, y aunque se han suscitado diversos cambios en dicho proceso, éste sigue representando una opción laboral atractiva, ya que económicamente resulta ser más redituable que los empleos en el territorio nacional. Para la población rural del país la migración hacia Estados Unidos es en muchos casos la única oportunidad real para mejorar sus condiciones de vida, tal es el caso de la comunidad de Godoy, perteneciente al municipio de Salamanca, Guanajuato.

En este sentido, el artículo pone atención en la migración masculina internacional de la comunidad antes mencionada y centra su análisis en las repercusiones que tal situación tiene para las madres y las esposas de los migrantes y su grupo doméstico. Este escrito es resultado del trabajo de campo realizado en 2007 y donde se trabajó con 30 grupos domésticos en los cuales existía migración masculina. La información se obtuvo mediante la aplicación de cuestionarios y entrevistas semiestructuradas, mismas que se analizan desde la perspectiva de género.

La articulación del trabajo es la siguiente: primero, se presenta la revisión de literatura, después, se muestra el ámbito de estudio, enseguida se menciona la metodología y asimismo se expone el análisis de los resultados obtenidos en campo, finalmente, se realiza una conclusión.

\section{Revisión de literatura}

\section{Elementos para entender el fenómeno de la migración}

El concepto de migración por sí mismo resulta complicado de definir, esto debido a sus múltiples implicaciones. Los economicistas han sido los pioneros en el estudio migratorio, aunque recientemente ha sido muy cuestionado por otras ciencias su argumento de que el desplazamiento de las personas de un país a otro se reduce sólo a una cuestión salarial.

En este sentido, debe reconocerse además de la mejora salarial otros elementos que intervienen en la decisión de migrar, tales como que la decisión misma se puede tomar de manera individual o grupal, así como que el migrante se establece en un contexto totalmente nuevo para él y que ade- 
más, el desplazamiento no implica una ruptura total con el país de origen. Tales elementos invitan a considerar la siguiente definición sobre migración:

La migración se puede entender como el tránsito de un espacio social, económico, político y/o cultural a otro, con el fin de desarrollar un determinado proyecto y tratar de responder a unas determinadas expectativas personales o de grupo. Se trata de un proceso que se inicia en el país de origen, antes incluso de que se tome la decisión de emigrar y que se cuente con los medios para hacerlo. Su gestación comienza más bien en el momento en el que se da la conjunción de condiciones y estímulos necesarios: sentimiento de insatisfacción o precariedad (objetiva o no) y expectativas de cambio y ascenso social, antecedentes migratorios de la familia, círculo de amigos o vecindario, presión social y posesión de los recursos mínimos necesarios para migrar (Lacomba, 2001:11).

\section{Teoría neoclásica}

La teoría neoclásica es considerada por excelencia el enfoque tradicional para explicar el fenómeno migratorio. Bajo la explicación neoclásica, la migración es resultado de las diferencias salariales, mismas que corresponden a la lógica del mercado laboral, es decir, a la oferta y la demanda de trabajo; es por ello que este punto de vista refiere regiones de expulsión y atracción (Conroy et al., en Suárez y Zapata, 2004). Desde esta perspectiva, la decisión de las personas por desplazarse de un lugar a otro es tomada con base en un balance costo-beneficio; la resolución de migrar depende exclusivamente de que la comparación resulte favorable a su bienestar. No obstante, para tomar dicha decisión se deben considerar aspectos como la reunificación familiar, verse obligados a salir, estudiar y conocer, entre otros.

\section{Migración laboral internacional}

De acuerdo con Marroni (2005), la migración es una forma en la que los países se liberan de tensiones tanto políticas como económicas a partir de los constantes movimientos de migrantes. ${ }^{1} \mathrm{Al}$ mismo tiempo que los

$\overline{{ }^{1} \text { Marroni (2005) }}$ hace referencia exclusivamente a la migración México-Estados Unidos. 
países con una economía débil se liberan de la presión social por la falta de empleos, los países desarrollados pueden absorber esa mano de obra sobrante gracias a que cuentan con una economía fuerte (Ludger, 1997). Es importante reconocer el carácter social de la migración y establecer que tanto en los lugares de salida como en los de llegada se provocan cambios. De esta manera y de acuerdo con Ludger, la migración internacional debe "concebirse como un fenómeno social, que provoca el surgimiento de realidades sociales cualitativamente nuevas, más allá de los acostumbrados arraigos espaciales de la región de llegada y de destino" (Ludger, 1997:33).

Los beneficios que se obtienen en los países expulsores de migrantes son pocos en comparación con los costos que ello implica. Países como México han experimentado una gran pérdida cultural por la interacción que tienen los migrantes en contextos diferentes a los que se viven en el lugar de origen, esto a su vez provoca que las identidades individuales y colectivas se transformen (Luin, 1997).

En nuestro país la migración es un suceso que se considera histórico pues se ha hecho presente desde hace más de cien años. Jorge Durand (2000) considera que la historicidad, la vecindad y la masividad son los elementos que distinguen a la migración nacional respecto de otras migraciones transnacionales. En México el principal elemento que ha propiciado los grandes flujos migratorios son las severas y recurrentes crisis económicas, siendo el campo mexicano el más afectado, de tal manera que la población migrante había sido exclusivamente rural; sin embargo, a últimas fechas ha aumentado la población urbana que emigra a Estados Unidos (Inmujeres, 2006; Suárez y Zapata, 2004).

Aunque en el país ha existido la migración por más de un siglo, es preciso mencionar que históricamente la región occidente ha sido protagonista de este fenómeno. Durand (1991) menciona que para los años treinta y cuarenta del siglo xx los estados con mayor expulsión de migrantes a Estados Unidos fueron Guanajuato, Jalisco y Michoacán; actualmente existe la misma tendencia ya que para el año 2005 estos tres estados se situaron entre las principales entidades expulsoras de emigrantes (INEGI, 2005). Con base en los argumentos brindados por Durand (2000), el occidente se distingue de los otros estados por la historicidad y la masividad de sus corrientes migratorias. 


\section{Tipos de migración}

Un concepto intrínseco a la migración es la movilidad, es decir, el desplazamiento de un lugar a otro; este proceso es considerado como "trayectoria migratoria” (Macías, 1997). La movilidad puede darse de manera temporal o ser permanente. Por lo tanto, se puede diferenciar la migración a partir del tiempo que se permanece fuera de la región o país de origen: a) migración permanente: es cuando los individuos salen a una determinada región o país y se establecen a vivir de manera definitiva en otro territorio; y b) migración temporal: cuando las persona se transportan continuamente de un territorio a otro (Gamio, 1991).

Otra clasificación de los flujos migratorios es la que se hace a partir del espacio en que se da la movilidad. Macías (1997) propone cuatro tipos distintos de migración: 1) migración por etapas: implica que los desplazamientos se den de manera paulatina, es decir, primero traslados locales, después nacionales y finalmente internacionales; 2) migración local o regional: los desplazamientos están limitados a ese espacio específico; 3 ) migración nacional: cuando los traslados se realizan en el territorio nacional, y puede o no haberse dado antes la migración local; y 4) migración internacional: refiere desplazamientos que traspasan las fronteras nacionales.

\section{Participación de las mujeres en la migración}

Según Álvarez (2005), las formas de participación de las mujeres en el fenómeno migratorio son tres: a) mujeres que migran acompañando a los varones de su familia; $b$ ) mujeres que migran por su propia cuenta; y $c$ ) mujeres que se quedan a cuidar a la familia mientras el compañero migra. Para las mujeres que se quedan en la espera de su hijo o su marido, su jornada de trabajo se duplica o triplica, según sea el caso, ya que

[...] estas mujeres, por lo general, no sólo se ocupan de cumplir con los roles que tradicionalmente se les ha asignado (cuidar a las y a los hijos y atender el funcionamiento de la casa) sino que también asumen el papel que el compañero, por su ausencia, deja de cumplir, ocupándose en actividades productivas remuneradas o en las laborales del campo para sostener económicamente a su familia (Álvarez, 2005:83). 


\section{Algunas consecuencias de la migración para los integrantes de los grupos domésticos}

La migración no sólo genera cambios en las actividades que se desempeñan al interior de los grupos domésticos, ya que al existir una constante interacción (directa e indirecta) con una cultura más abierta y el hecho de que las mujeres pasen largas temporadas sin la compañía de su esposo, provoca que los conflictos entre géneros y generaciones se agudicen, dando como resultado "nuevos arreglos y reorganizando las posiciones de los miembros que conforman el grupo" (Rivermar, 2002:73).

En los grupos domésticos que han experimentado la migración masculina, las mujeres esposas y las madres tienen que desempeñar las actividades que éstos realizaban; ${ }^{2}$ no obstante, esto no las exime de realizar "las tareas propias de su género", es decir, educar a las hijas e hijos, lavar, planchar, hacer de comer, etcétera. También es común que los hombres formen otros hogares en el lugar de destino y, por lo tanto, las mujeres tienen que asumir la jefatura del hogar y las responsabilidades que esto conlleva. "De esta manera a las mujeres con esposos migrantes les corresponde asumir los papeles de: madres, educadoras, jefas de familia, administradoras y generadoras del ingreso familiar" (Alvarado, 2004:244).

\section{Los grupos domésticos}

Los grupos domésticos son la forma predominante de residencia en el medio rural, esto se debe a que de manera grupal es más fácil enfrentar las eventualidades que se presenten; el objetivo es entonces "ayudarse mientras se ayuda". ${ }^{3}$ Para las unidades domésticas la reproducción es su principal meta y se realiza en dos ámbitos: el primero tiene que ver con el proceso productivo, el cual brinda los elementos necesarios a los integrantes del grupo para su reproducción física; el segundo hace refe-

\footnotetext{
${ }^{2}$ Entre las cuales se destacan la manutención inmediata del grupo doméstico, administrar todos los recursos del grupo, realizar las actividades agrícolas y asumir los cargos que la comunidad le ha designado al varón,

${ }^{3}$ La finalidad de las personas al formar un grupo doméstico es obtener beneficio (principalmente económico) de dicha situación. De tal manera que al ayudar a los demás integrantes del grupo se asegura el beneficio individual.
} 
rencia a los elementos socioculturales que confluyen en las comunidades y que a su vez influyen marcadamente en la organización de los grupos, buscando con ello que esos elementos se transmitan de generación en generación.

Autoras como Lomnitz (2006), Oliveira y Salles (1989), Harris (1986) y otras han tomado como sinónimos a la unidad doméstica y el grupo doméstico. Para el caso de esta investigación se asumirá dicha postura. Se retoma la definición hecha por Oliveira y Salles: "El concepto de unidad doméstica alude a una organización estructurada a partir de relaciones sociales establecidas entre individuos unidos o no por lazos de parentesco, que comparten una residencia y organizan en común la reproducción cotidiana” (1989:14). Una vez conformado el grupo, las relaciones que se mantienen en su interior "pueden generar conflictos y solidaridades que al intervenir en los grados de cohesión dan mayor o menor grado de continuidad a familias y unidades domésticas" (Oliveira y Salles, 1989:15).

Cabe mencionar que las relaciones entre géneros y generaciones expresan en mayor medida la cohesión o el conflicto en la unidad doméstica, eso se debe a que en torno de estas relaciones convergen el poder y la violencia como elementos para ejercer autoridad. Además, elementos como el estado civil, la educación, el aporte económico que se hace al fondo común del grupo, el ser o no propietario de los medios de producción, el grado de poder que se posee, la posición que se ocupe dentro del grupo, influyen para que las relaciones sean solidarias o conflictivas.

La característica esencial que define a los grupos domésticos son las relaciones que mantienen los individuos que los conforman, y que pueden ser económicas, de parentesco, de residencia o de reciprocidad y tener como finalidad la reproducción social del grupo. Esta forma de organización va más allá de una residencia compartida y de lazos de parentesco. ${ }^{4}$ Los elementos antes mencionados permiten argumentar que no existe un modelo único de grupo doméstico.

${ }^{4}$ El parentesco es la característica que define a la familia y puede o no estar presente en la unidad doméstica. 


\section{Grupos domésticos rurales}

Los grupos domésticos rurales, según Chayanov, retomado por Oliveira y Salles (1989), destacan principalmente por los medios de producción y la fuerza de trabajo, puesto que

[...] el concepto de grupo o unidad doméstica en el contexto rural, permite vincular las actividades de producción y consumo y analizar las interrelaciones entre el grupo familiar y la unidad productiva, aspectos cruciales en la reproducción de los grupos campesinos. La unidad doméstica campesina presenta una amplia integración de la vida de la familia con la unidad productiva, la producción se basa en el trabajo familiar y los frutos de la actividad económica se dirigen a la subsistencia del grupo doméstico (Oliveira y Salles, 1989:15-16).

Actualmente los grupos domésticos campesinos no alcanzan a satisfacer con su producción de autoconsumo necesidades como vivienda, educación, salud, vestido, etcétera, y se ven obligados a generar estrategias para cubrirlas; es decir, implementan nuevas formas de organizar la producción y el trabajo, con lo cual redefinen las condiciones que les permiten asegurar su supervivencia. Algunas de las estrategias utilizadas comúnmente son: intensificación del trabajo familiar, diversificación de labores, venta de la fuerza de trabajo, en donde una de sus modalidades es la migración, y venta de alimentos procesados, entre otras. ${ }^{5}$ Cabe destacar que en esta reconfiguración de las actividades del grupo doméstico, las mujeres son las más afectadas pues su jornada de trabajo aumenta así como sus responsabilidades.

La reproducción de las unidades domésticas rurales no se circunscribe entonces sólo al aspecto físico, dicha reproducción abarca además elementos culturales y simbólicos; así, la organización de las familias campesinas "tiene (por sus rasgos tradicionales) pautas de organización articuladas en torno a costumbres que se transmiten y heredan generacionalmente" (Salles, 1991:72).

\footnotetext{
${ }^{5}$ Salles (1991) establece que la disminución del consumo puede ser considerada también otra estrategia empleada por el grupo doméstico.
} 


\section{Relaciones desiguales en los grupos domésticos}

Las unidades domésticas organizan sus actividades con base en la división genérica del trabajo, la cual implica una separación/división entre los supuestos ámbitos privado o doméstico desempeñado casi siempre por las mujeres y el público, preferentemente masculino (Harris, 1986; Salles, 1991). En dicha división se consideran de mayor importancia las actividades que se realizan en la esfera pública, ${ }^{6} \mathrm{y}$, por el contrario, aquellas que se desempeñan en el ámbito doméstico son menospreciadas. Esto ocasiona desigualdad entre géneros al interior de los grupos domésticos.

La diferenciación que se hace de las personas a partir de las características sexuales que poseen es, probablemente, la forma más común en que se ejerce la desigualdad al interior de las unidades domésticas, y es a partir de la cual se desencadena una serie de situaciones que ponen en desventaja a las mujeres. La cotidianidad con que se lleva a cabo este tipo de relaciones ha provocado una "naturalización" de las conductas que reproducen la falta de igualdad entre hombres y mujeres.

La edad es también un factor que determina la posición de los individuos dentro de la unidad. Es por ello que se debe considerar que las diferencias tanto de edad como de sexo son elementos que permiten excluir a las personas del poder y por lo tanto es posible sujetarlas a los decretos de las personas que sí lo ejercen. En este sentido, "los adultos mayores ancianos tienen mayor prestigio que los jóvenes, éstos sobre los niños, etc. Respecto al sexo, las mujeres son siempre subordinadas a los hombres, primero por el padre, luego por el esposo y finalmente por sus hijos si éstas son viudas" (Ángeles et al., 1996:130).

\section{Participación de las mujeres en los grupos domésticos rurales}

Las tareas que desempeñan las mujeres son múltiples, y el contexto influye de manera determinante en estas actividades. Distintas investigaciones

\footnotetext{
${ }^{6}$ Salles considera que hay "una especie de estatus generado y transferido por el protagonista que tiene como escenario el ámbito público, que es la instancia relacional atribuidora de status" (1991:64). De esa manera, las actividades que realizan los hombres en la esfera pública resultan ser de mayor importancia que las que desempeñan las mujeres.
} 
han demostrado que la jornada de trabajo para las mujeres es más intensa en el medio rural que en el urbano. Debido al interés por demostrar la importancia de la participación femenina en los grupos domésticos rurales, se retoma el estudio de caso realizado por Mercado y Zapata (1995); ellas encontraron que

[...] las mujeres participan en 10 actividades de tecnología tradicional de las 14 que se realizan en total (las otras 4 son mecanizadas); además, $61.5 \%$ de las actividades de la parcela se realizan con mano de obra no remunerada. Pero la mujer también participa vendiendo o transformando la producción de traspatio. Venden animales y alimentos procesados: barbacoa, tamales, antojitos, fruta de cosecha, tienen tiendas de abasto, etcétera. En fin, incursiona en el comercio en pequeña escala, con fines de incrementar el ingreso. Además, dedica más tiempo a la compra de alimentos debido a que tiene que buscar donde sean más baratos con el fin de estirar sus pocos recursos (Zapata y Mercado, 1995:176-177).

Hay ocasiones en que las mujeres además de ayudar en las actividades agrícolas, desempeñan algún cargo en su comunidad o trabajan fuera de su hogar para percibir un ingreso extra. Y sin embargo, ninguna de estas actividades las libera de sus tareas domésticas cotidianas.

\section{Resumiendo}

La migración internacional es indudablemente una respuesta a las malas condiciones económicas del país. La mayoría de los migrantes se van a Estados Unidos para obtener un empleo mejor remunerado, no obstante, la migración tiene implicaciones no sólo para quien migra, pues esta decisión involucra al padre, la madre, la esposa, la hija, el hijo y todos aquellos que forman parte del grupo doméstico del migrante. Para las unidades domésticas la migración resulta una estrategia común de reproducción, pues se aspira con ello a que mejoren sus condiciones económicas. La unidad al sufrir la ausencia de alguno de sus integrantes busca mecanismos que le permitan reorganizar sus actividades cotidianas y para ello alguien debe desempeñar las actividades que el migrante realizaba. Generalmente son las esposas o las madres de los migrantes las que realizan dichas ac- 
tividades, con lo cual su jornada de trabajo se incrementa. Aunque esta situación también les permite a las mujeres incursionar en ámbitos que anteriormente les pudieron ser prohibidos.

\section{Ámbito de estudio}

\section{Ubicación geográfica: municipio de Salamanca ${ }^{7}$}

Son 46 los municipios que conforman el estado de Guanajuato, entre los cuales se ubica Salamanca. Este municipio se localiza en el suroeste de la entidad. Limita al norte con los municipios de Irapuato y Guanajuato, al noreste con San Miguel de Allende, al este con Santa Cruz de Juventino Rosas y Villagrán, al sureste con Cortázar, al sur con Jaral del Progreso y Valle de Santiago, y al oeste con los municipios de Irapuato y Pueblo Nuevo (véase figura 1). Para el año 2005 Salamanca contaba con una población total de 143838 habitantes, de los cuales 74755 eran mujeres y 69083 eran hombres.

\section{Ubicación geográfica: Godoy}

Godoy cuenta con una población total de 669 habitantes, de los cuales 358 son mujeres y 311 son hombres. Es una de las 580 localidades que conforman el municipio de Salamanca y se sitúa a los $101^{\circ} 05^{\prime} 20^{\prime \prime}$ de longitud del Meridiano de Greenwich y a los 20 33' 29" de latitud. Su altura sobre el nivel del mar es de 1720 metros (INEGI, 2005). Esta comunidad se localiza al sureste del municipio, limitando al norte con la comunidad Carmelita, al sur con la comunidad de Santa Catarina de Peña, al este con el municipio de Villagrán y al oeste con las comunidades de Conejos y la Virgen (véase figura 1).

Sólo un microbús transita por el camino dos veces al día, la ruta es Salamanca-Godoy; los horarios son de 10 de la mañana con destino al centro de Salamanca y a las 14:00 horas regresa. Cabe señalar que ese transporte es utilizado principalmente para ir a comprar alimentos y calzado o para ir

${ }_{7}$ Los datos del municipio se obtuvieron del Anuario Estadístico del Estado de Guanajuato y del inegi 2005. 


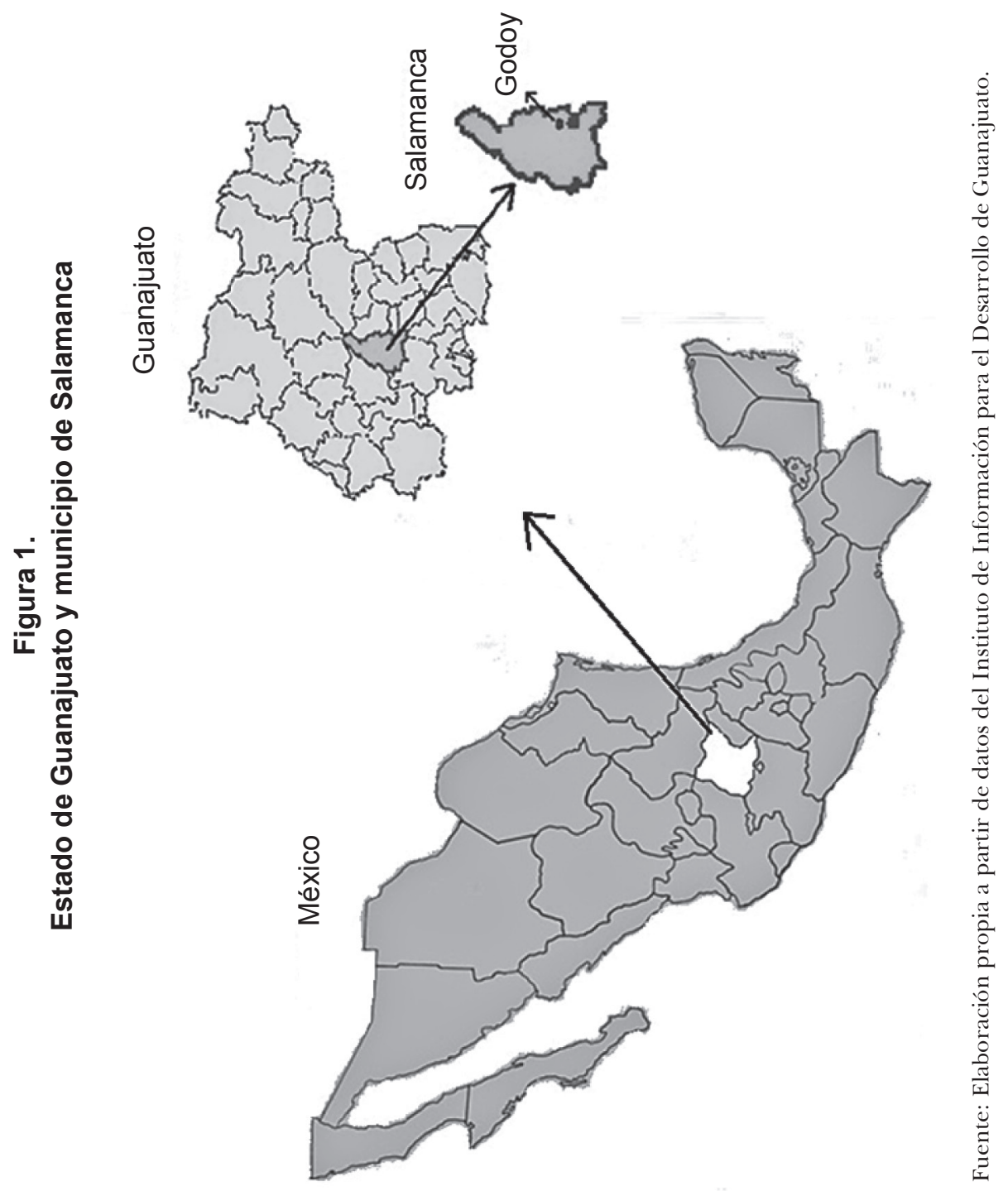


al servicio médico, del cual se carece en la comunidad. El tiempo de traslado en microbús desde la comunidad al centro de la ciudad de Salamanca es de aproximadamente 45 minutos.

\section{Metodología}

Para llevar a cabo la investigación en la comunidad de Godoy se emplearon los métodos cuantitativos y cualitativos. En lo que respecta al método cuantitativo, se utilizó la técnica de muestreo simple aleatorio y se recurrió a la encuesta pues con ella se puede "identificar y conocer la magnitud de los problemas que se supone o se conoce en forma parcial o imprecisa" (Rojas, 2002:221). Se aplicaron 30 cuestionarios a grupos domésticos que presentaron migración masculina. Mientras que para el método cualitativo se aplicaron siete entrevistas semiestructuradas a informantes clave que tenían como particularidad ser las madres o esposas de los migrantes. El trabajo de campo se realizó durante el año 2007.

\section{Resultados}

\section{Los grupos domésticos: descripción general}

La migración internacional del jefe de la unidad o de alguno de los hijos fue el elemento indispensable para seleccionar los 30 grupos domésticos de estudio (se tomó en cuenta unidades que experimentaran en ese momento migración o donde el migrante estuviera de regreso). La población total con la cual se trabajó fue de 154 personas, donde 74 eran mujeres, lo cual equivale a $48.0 \%$, y 80 hombres, cantidad que equivale a $52.0 \%$ del total de la población.

El número de integrantes por grupo doméstico varió de 2 hasta 14 individuos, siendo preponderantes aquellos de cuatro, cinco y seis integrantes ya que en ellos se concentraban 21 unidades domésticas, es decir, $70 \%$. En estas 21 unidades se concentró $68.8 \%$ de la población, porcentaje que es igual a 106 personas. Por otro lado, los grupos menos representativos fueron los integrados por dos o 14 personas, aglutinando un porcentaje muy bajo de la población total existente en las unidades domésticas estudiadas (véase cuadro 1 ). 


\section{Cuadro 1.}

Número de integrantes del grupo doméstico

\begin{tabular}{|c|c|c|}
\hline Número de integrantes & Grupos domésticos & Porcentaje \\
\hline 2 & 2 & 6.7 \\
3 & 3 & 10.0 \\
4 & 6 & 20.0 \\
5 & 8 & 26.7 \\
6 & 7 & 23.3 \\
7 & 3 & 10.0 \\
14 & 1 & 3.3 \\
\hline Total & 30 & 100.0 \\
\hline
\end{tabular}

Fuente: Trabajo de campo, 2007.

En lo referente a la edad de los integrantes de las unidades domésticas,

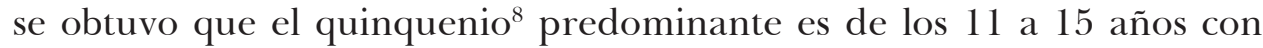
$15.6 \%$, lo cual muestra la existencia de un porcentaje considerable de adolescentes. La población considerada como joven aglutina a los siguientes grupos: 16 a 20 años, 21 a 25 años y 26 a 30 años, los cuales representan en conjunto $31.8 \%$, es decir, casi una tercera parte del total. Mientras que las personas de 6 a 10 años equivalen al 11.0\%. Por otro lado, a partir del quinquenio de 31 a 35 años hasta el de 66 a 70 años la población tiende a disminuir, aunque en algunos casos aumenta, si bien este incremento no llega ni a un punto porcentual. Finalmente, los infantes que no cuentan con edad escolar, que va de 0 a los 5 años, representan tan sólo 7.1\%. Estos datos permiten ver que gran parte de la población estudiada se conforma por niños, adolescentes y jóvenes (véase cuadro 2).

Para el año 2005, según el Inegi, en el municipio de Salamanca, Guanajuato, había un total de 143838 habitantes. El mayor número de personas se encontraba entre los 5 y 19 años de edad, aglutinando $30.6 \%$ del total de la población existente en Salamanca. Estas cifras revelan que tanto en la comunidad como en el municipio los niños, adolescentes y jóvenes son la población mayoritaria.

A continuación se presentan las actividades realizadas por todos los integrantes de cada una de las unidades domésticas, se incluye también a las

\footnotetext{
${ }^{8}$ Para facilitar la comprensión de la edad de los integrantes, ésta se presenta por quinquenios.
} 
personas que en el momento en que se realizó el trabajo de campo habían migrado. Esto con la finalidad de presentar un panorama general sobre todas las actividades que se realizan en la población con la cual se trabajó; más adelante se especifica sobre las actividades de los migrantes.

\section{Actividades realizadas por los integrantes de las unidades domésticas}

Como se puede ver en el cuadro 3, las actividades más importantes son: a) estudiantes, con $31.2 \%$, y b) trabajo doméstico, con $25.3 \%$, pues en comparación con las demás existe una diferencia porcentual considerable. Retomando el aspecto de la edad, podemos darnos cuenta de que al existir un alto porcentaje de niños y jóvenes en los grupos domésticos, es lógico el número elevado de estudiantes.

El trabajo doméstico ocupa el segundo lugar en representación, esto se puede explicar desde la perspectiva de género pues según la asignación de roles por sexo las mujeres deben ocuparse del hogar. Actividades como la construcción, obrero, agricultura, jornalero, jardinero, ayudante

\section{Cuadro 2.}

Edad de los integrantes de los grupos domésticos

\begin{tabular}{|c|c|c|}
\hline Rangos de edad & Número de personas & Porcentaje \\
\hline $0-5$ & 11 & 7.1 \\
$6-10$ & 17 & 11.0 \\
$11-15$ & 24 & 15.6 \\
$16-20$ & 16 & 10.4 \\
$21-25$ & 14 & 9.1 \\
$26-30$ & 19 & 12.3 \\
$31-35$ & 16 & 10.4 \\
$36-40$ & 13 & 8.4 \\
$41-45$ & 5 & 3.3 \\
$46-50$ & 6 & 3.9 \\
$51-55$ & 4 & 2.6 \\
$56-60$ & 6 & 3.9 \\
$61-65$ & --- & ----- \\
$66-70$ & 3 & 2.0 \\
\hline Total & 154 & 100. \\
\hline
\end{tabular}

Fuente: Trabajo de campo, 2007. 


\section{Cuadro 3.}

Actividades desempeñadas

\begin{tabular}{|l|c|c|}
\hline \multicolumn{1}{|c|}{ Actividad } & Personas & Porcentaje \\
\hline Estudiante & 48 & 31.2 \\
Trabajo doméstico & 39 & 25.3 \\
Construcción & 12 & 7.8 \\
Obrero(a) & 9 & 5.9 \\
Ninguna & 9 & 5.9 \\
Campesino(a) & 8 & 5.2 \\
Jornalero(a) & 8 & 5.2 \\
Jardinería (Yarda) & 7 & 4.5 \\
No sabe & 6 & 3.9 \\
Comerciante & 2 & 1.3 \\
Servicio doméstico & 2 & 1.3 \\
Ayudante general de casa & 1 & 0.6 \\
Trailero & 1 & 0.6 \\
Velador & 1 & 0.6 \\
Empleado & 1 & 0.6 \\
\hline Total & 154 & 100 \\
\hline
\end{tabular}

Fuente: Trabajo de campo 2007.

general en casa, trailero, velador y empleado son en su mayoría realizadas por varones y de manera aislada parece que son poco representativos, no obstante, en sumatoria llegan a representar 31.0\%. De esta manera, se observa una correlación entre hombres y trabajo asalariado. Finalmente, el sector de la población que no realiza ninguna actividad remunerada es porque no tiene la edad suficiente para asistir a la escuela, mientras que de los que no se sabe a qué se dedican, es porque se encuentran en Estados Unidos y no dan esa información a sus familiares (véase cuadro 3).

En lo que respecta a las actividades domésticas, se encontró que de las 30 mujeres encuestadas, 100\% realiza esta actividad, aunque hay dos casos que también desempeñan un trabajo asalariado: una de estas mujeres se dedica a trabajar sus tierras y la otra se dedica al comercio ya que tiene su propia tienda. Por otro lado, en cuanto a las actividades que realizan los hombres, especialmente aquellos que son los jefes de las unidades domésticas, encontramos que sin excepción éstos realizan un trabajo asalariado. Para ellos, las tareas del hogar las efectúan sólo de manera excepcional; por ejemplo cuando la esposa por enfermedad no puede realizarlas. 
Cuadro 4.

Actividades desempeñadas por las mujeres

\begin{tabular}{|l|c|c|}
\hline \multicolumn{1}{|c|}{ Actividad desempeñada } & Casos & Porcentaje \\
\hline Agricultura & 1 & 3.33 \\
Comerciante & 1 & 3.33 \\
Trabajo doméstico & 28 & 93.33 \\
\hline Total & 30 & 100.00 \\
\hline
\end{tabular}

Fuente: Trabajo de campo, 2007.

\section{Educación}

Los datos obtenidos de las unidades domésticas respecto de lo educativo fueron los siguientes: el número total de hombres con los cuales se trabajó fue de 81 , de los cuales dos no tenían edad escolar. De los 79 restantes, seis no estudiaron -estas personas son las que tienen mayor edad-. El nivel máximo educativo de los hombres en Godoy es la secundaria. Todos los hombres que asisten a la escuela lo hacen de acuerdo a la edad que se estipula en cada nivel educativo (véase cuadro 5).

El total de las mujeres que había en las unidades domésticas fue de 70 , de las cuales sólo tres de ellas no tenían edad escolar. Fueron siete mujeres las que no estudiaron, la edad de éstas varía de los 47 hasta los 70 años; al igual que en el caso de los hombres, este grupo de mujeres es el que representa a las de mayor edad. La primaria completa es el máximo de grado de estudio entre las mujeres de Godoy -cabe señalar que la secundaria terminada también ocupa un lugar importante-. Aquellas niñas y adolescentes que se encuentran estudiando, lo hacen de acuerdo con la edad permitida en cada uno de los niveles educativos (véase cuadro 5).

\section{La migración en los grupos domésticos}

El análisis de la migración masculina es el elemento primordial para comprender los cambios que desencadena en las madres, las esposas y los grupos domésticos, los cuales se mencionarán más adelante. De las 154 personas con las cuales se trabajó, 38 de ellas eran migrantes, cantidad que representa $24.7 \%$, es decir, casi una cuarta parte del total de población, lo cual es considerablemente representativo. Por otro lado, se encontró que 


\section{Cuadro 5.}

Grado de escolaridad por edad y género

\begin{tabular}{|l|c|c|c|c|}
\hline \multirow{2}{*}{ Grado de escolaridad } & Personas & Rango de edad & Personas & Rango de edad \\
\cline { 2 - 5 } & \multicolumn{2}{|c|}{ Hombres } & \multicolumn{2}{|c|}{ Mujeres } \\
\hline Estudia preescolar & 4 & $3-6$ años & 3 & $3-5$ años \\
Estudia primaria & 15 & $6-12$ años & 10 & $6-11$ años \\
Estudia secundaria & 7 & $12-14$ años & 6 & $12-15$ años \\
Estudia bachillerato & 1 & $15-15$ años & --- & ---------- \\
Primaria completa & 13 & $21-45$ años & 20 & $17-48$ años \\
Secundaria completa & 19 & $17-45$ años & 17 & $16-49$ años \\
Bachillerato completo & 1 & $21-21$ años & -- & ---------- \\
Primaria incompleta & 3 & $17-27$ años & 5 & $21-55$ años \\
Secundaria incompleta & 4 & $21-38$ años & 1 & $34-34$ años \\
Bachillerato incompleto & 1 & $21-21$ años & 1 & $20-20$ años \\
No estudió & 6 & 53-70 años & 7 & $47-70$ años \\
\hline
\end{tabular}

Fuente: Trabajo de campo 2007.

en las 30 unidades domésticas estudiadas, la población en edad de trabajar es de 95 personas, de tal manera que los migrantes representan $40 \%$ del total de personas en edad de trabajar.

Haciendo una diferenciación por género, se halló que de los 38 casos de migración, 34 eran de hombres, y eso representa $89.5 \%$, mientras que solamente cuatro eran representados por mujeres, cantidad que equivale tan sólo a 10.5\%. Comparando dichas cantidades con la población total de estudio, obtenemos que los hombres migrantes representan $22.1 \%$, mientras que las mujeres solamente 2.6\%. Cabe mencionar que los datos aquí registrados son de personas que han migrado en algún momento o de aquellos que en este momento son migrantes.

\section{Migrantes por grupo doméstico}

La cantidad de migrantes por grupo doméstico varía de uno de tres individuos. Es decir, el promedio de migrantes por grupo doméstico es uno. Se encontró que de las 30 unidades estudiadas, 23 de ellas habían expulsado sólo a un migrante, esto equivale a $76.7 \%$ del total de migrantes. Otros seis grupos domésticos expulsaban a dos migrantes, lo que corresponde a 
$20 \%$, y finalmente, sólo un grupo expulsaba a tres migrantes, lo que equivale a 3.3\%. Estas cifras permiten concluir que en Godoy la constante de expulsión de migrantes hacia Estados Unidos en las unidades domésticas es una persona.

\section{Tipo de migración}

Retomando la clasificación de migración por temporalidad que realiza Macías (1997), en donde establece la existencia de dos tipos de migración, permanente y temporal, y con la información obtenida en campo, se ha establecido una clasificación propia. De tal manera que para el caso de Godoy se observaron los siguientes patrones migratorios: a) retorno: personas que migraron (generalmente la razón fue laboral) y que en este momento se encuentran de nuevo en la comunidad; $b$ ) laboral: personas que migraron para obtener un trabajo mejor remunerado y que no tienen más de dos años como migrantes; y $c$ ) permanente: individuos que se han establecido por más de cinco años en Estados Unidos y que en algunos casos regresan a Godoy por periodos muy cortos en los cuales no trabajan.

Con base en la clasificación anterior, 26 de los migrantes se van a Estados Unidos por motivos laborales, lo que corresponde a $68.4 \%$ del total de la población migrante. ${ }^{9}$ El tipo de migración de retorno representa $15.8 \%$, y según estas mismas personas, por el momento no piensan volver a migrar ya que muchas de ellas tienen en este momento un trabajo estable en la comunidad o cercano a ella. Mientras que el número de personas que se ha establecido de manera permanente en territorio estadounidense asciende a seis, cantidad que representa $15.8 \%$. Según los propios familiares, los migrantes manifiestan de manera constante el anhelo de regresar algún día a Godoy; no obstante, las familias expresaron que esto es muy poco probable ya que en todas las ocasiones que han dicho que regresarían han terminado postergando dicho retorno (véase cuadro 6).

\footnotetext{
${ }^{9}$ Es importante subrayar que existen casos en donde la decisión de migrar aparentemente no corresponde a una mejora en el salario, pues ante la pregunta de por qué fue tomada la decisión de migrar algunas de las respuestas fueron: por conocer, ganas de irse, reunirse con sus familiares, entre otras, pero en casi todos los casos estas personas ya se encuentran trabajando en Estados Unidos; por dicha razón es que se les ha ubicado en este tipo de migración.
} 


\section{Cuadro 6.}

\section{Tipo de migración}

\begin{tabular}{|l|c|c|}
\hline \multicolumn{1}{|c|}{ Tipo de migración } & Número de migrantes & Porcentaje \\
\hline Laboral & 26 & 68.4 \\
Retorno & 6 & 15.8 \\
Permanente & 6 & 15.8 \\
\hline Total & 38 & 100.00 \\
\hline
\end{tabular}

Fuente: Trabajo de campo, 2007.

\section{La decisión de migrar}

Migrar es una decisión que en muchos casos suele involucrar a más personas que sólo al migrante, pues tal evento impacta en la vida y las actividades de los demás integrantes del grupo doméstico. En el caso de las unidades nucleares, quienes deciden son el jefe y su cónyuge; para las unidades extensas, y en los casos en donde el migrante es uno de los hijos, se toma la decisión entre los padres y el hijo. No obstante, en algunos casos la decisión de migrar es compartida por las madres o esposas, quienes a veces aceptan aunque no estén de acuerdo.

La principal motivación para migrar es mejorar las condiciones de vida de la unidad doméstica y sus integrantes; se busca, principalmente, construir una casa, tener ahorros, adquirir aparatos electrodomésticos y dar mejor alimentación, vestido y calzado a los hijos.

Para el caso de esta investigación se encontraron los siguientes motivos: a) búsqueda de trabajo (19 personas se han ido por este motivo, lo que representa 50\%); b) mejorar sus condiciones de vida (11 personas se han ido, lo que equivale a 29\%); c) ganas de irse (cuatro personas se fueron por esta razón, lo que representa 10.5\%); d) trabajar (dos de las personas entrevistadas $-5.3 \%$ de la muestra- iban de vacaciones y se quedaron a trabajar); e) aceptar una invitación (fueron invitados a irse); y f) reunirse con el cónyuge, razones estas últimas por las que sólo una persona migró (2.6\% respectivamente). Como se observa, la razón principal para irse al país vecino es obtener un mejor trabajo; aunque no de manera explícita, la búsqueda de mejores condiciones de vida, el irse de vacaciones y encontrar empleo involucran la búsqueda de trabajo. De ahí que sea el empleo lo que incita a la migración en la comunidad de Godoy. 
Se preguntó a las entrevistadas la razón por la cual migraron su esposo o hijo. María, de 30 años, esposa de un migrante, respondió: "Los planes eran hacer la casa y terminarla, tener un carro y una cuenta en el banco. Estamos construyendo la casa y a las otras cosas pues les estamos dando tiempo si es que se hacen y si no, todo depende de lo que pase, pues mi esposo sólo piensa estar allá un año más”. Por su parte, Rosa, de 36 años, también esposa de migrante, dijo: "Mi esposo se fue a Estados Unidos para terminar de aplanar la casa, de ponerle loseta y pintarla. También si se podía guardar algo de dinero y que las niñas anduvieran un poco mejor vestidas, mejor calzadas, que comieran mejor y también yo. Arreglar algunas cosas que teníamos... pues... mal también, y hasta el momento creemos que sí lo hemos logrado”.

Silvia, de 49 años de edad y madre de un migrante, expresó: "Mi hijo decía que se iba para hacer una casa, pero ahora ya no se quiere venir, dice que qué viene a hacer acá, que ni hay trabajo y que ya no se quiere venir y ya no mandó para hacer la casa, tiene su solar pero ya no ha mandado para hacer la casa" (es madre de cinco hijos y seis hijas).

Como puede percibirse en los testimonios, no todas las expectativas respecto de la migración se cumplen, y en algunos casos ninguna de las metas de la migración se ha visto consolidada. Algunos migrantes terminan por abandonar sus propios objetivos al darse cuenta que lo que dejaron en Godoy ya forma parte de su pasado y ofrece poco para su presente y futuro, fracturando así los planes trazados en sus unidades domésticas.

\section{Destinos de la migración}

El destino de los migrantes de Godoy es principalmente Estados Unidos, es decir, es una migración internacional. Cabe mencionar que durante el trabajo de campo se registró un caso de migración local: una mujer, madre soltera que trabaja en un municipio vecino. Los porcentajes de acuerdo con el tipo de migración son $97.4 \%$ internacional y $2.6 \%$ local. A continuación se presentan algunos resultados de la migración internacional.

La migración en Godoy tiene siete destinos diferentes de llegada en Estados Unidos, y de acuerdo con los datos obtenidos en las unidades 
domésticas con las cuales se trabajó, la preferencia de los migrantes se distribuye de la siguientes manera: Texas 35.1\%, Florida 21.6\%, California $18.9 \%$, Oklahoma 5.4\%, Kansas 5.4\%, Arizona 5.4\% y Wisconsin 2.7\%. El $5.4 \%$ restante no se sabe su destino, pues sus familiares no cuentan con esta información.

\section{Implicaciones de la migración para las mujeres y el grupo doméstico}

En Godoy la incorporación de las mujeres al trabajo asalariado, cuando se presenta el fenómeno de la migración, no es un escenario que se haga presente, por lo cual la migración masculina representa para las mujeres la continuidad en la realización de las actividades domésticas, sumándose aquellas actividades que eran realizadas o compartidas con el migrante, como dar de comer a los animales, podar el pasto, ir por leña, el cuidado de los menores, entre otras. De tal manera que dicha situación resulta benéfica para las unidades domésticas pues con ello se logra tener un mejor ingreso y constante, mejorando así las condiciones de vida.

Existen también repercusiones negativas para los hijos, las esposas y las madres de los migrantes, pues la ausencia prolongada de estos integrantes genera sentimientos de tristeza, preocupación y abandono. Además de estas emociones, para las esposas la realización de sus actividades cotidianas y su vida misma se tornan un pesar con la ausencia de su cónyuge, así también tienen que reprimir su sexualidad (Martínez, 2005).

A continuación se presentan las respuestas de algunas de las entrevistadas cuando se les hizo la pregunta sobre las implicaciones de la migración para su unidad doméstica. Alicia, madre de migrante, de 47 años y que vive en unión libre, comentó:

Mi hijo pensó irse para hacer su casa, por eso compró un pedazo de terreno y estaba haciendo su casa, se quedó como a la mitad pues la estaba haciendo muy grande; después ya nomás ya no hablo y se acabó todo. Yo veo mal que mi hijo no me hable, porque él como hijo mío debería por lo menos hablarme para uno saber que está bien y se acuerda de uno. 
Antonia, de 60 años, madre de dos migrantes y viuda, respondió:

Pues el beneficio fue que tuvieran su casa, pero lo que no fue beneficio es que las dejaron solas [a sus nueras]. Eso es como una meta que se hacen, porque uno se sacrifica al irse y otro para estar sola y a cargo de la familia, y eso también es triste. No pos yo no creo que sea beneficio que estén allá porque por lo mismo que ellos se van uno ya nos los ve, ya no están con uno ni un ratito, nomás por el teléfono cuando le hablan a uno. Ese es el que no es beneficio para uno [para quienes se quedan]. Yo digo que el norte es roba hijos, roba maridos, roba hijas, todo; para mí ese es mi pensar, a lo mejor será porque ya estoy bien harta de estos años, de esa forma en que ellos están distanciados de uno. Es que cuando están por allá lejos, les avisan y es cuando uno ya no está, ya para qué. Si el dinero no es la felicidad, para mí es que ellos estén con uno.

Verónica, madre de migrante, con 48 años de edad, comentó:

Yo pienso que el norte no fue para mi hijo, porque él no se superó nada, él está como si se acabara de ir. Él realmente es un hombre que no supo salir adelante, porque ya ahorita con tanto tiempo que tenía allá [su hijo tiene más de 10 años de migrante], ya hubiera hecho algo y no tiene nada.

Para Rosa, esposa de migrante, de 36 años y perteneciente a un grupo doméstico nuclear, la ausencia de su esposo tiene implicaciones tanto benéficas como negativas. Opinó lo siguiente:

Los beneficios de que mi esposo se haya ido es en primer lugar que si se enferman las niñas ya tenemos dinero para ir al doctor y ya si uno se enferma puede ir más al médico; también que ellas andan un poco mejor calzadas y están mejor comidas. Lo malo es que él está lejos de nosotros, que si hay algún problema lo tengo que solucionar yo sola y también si me siento mal nada más yo sé y cuando él estaba pues ya compartía con él los problemas, y ya entre los dos nos apoyábamos.

Los testimonios anteriores evidencian el hecho de que para las mujeres de Godoy la migración es una solución a los bajos salarios y a la escasez 
de empleo, que impiden satisfacer las necesidades básicas en las unidades domésticas. Por otro lado, también se señalan aspectos negativos de la migración, como en Marroni (citada en Suárez y Zapata, 2004); entre éstos está la desintegración familiar, el incremento de las responsabilidades para las mujeres ante un nuevo escenario y la baja autoestima cuando los hombres incumplen su compromiso de proveedor. Esta última situación afecta también a los hijos e hijas, creando con ello tensiones al interior de la unidad.

Otra de las interrogantes planteadas a las mujeres fue si la migración masculina ha generado cambios en la percepción que tienen respecto del comportamiento habitual de los hombres y de las mujeres. Y si la migración de su esposo o hijo la ha hecho cambiar a ella en su comportamiento cotidiano y si el migrante ha experimentado algún cambio en sus patrones tradicionales.

Maribel, de 39 años y esposa de un migrante, describió su situación de la siguiente manera:

A mí sí me cambió el que mi esposo se haya ido, antes de que él se fuera yo era bien cobarde para muchas cosas y también era bien penosa hasta para preguntar cualquier cosa. A mí sí me cambió que él se fuera, eso me hizo más fuerte, se me quitó lo tímida y también le echo muchas ganas a todo. Y mi esposo también ha cambiado, él antes era más duro y más agrio con la gente, y ahora llega un poquillo más cariñoso con la gente. La primera vez que vino como que le valían las cosas y hora valora un poco más a la gente.

Rosa, de 36 años y esposa de migrante, expresó:

Para mí ahora que mi esposo se fue las cosas sí cambiaron porque ya no estando ellos uno tiene que tomar más decisiones. Ahora que él está allá me dice que él se hace todas sus cosas, su lonche, comida, cena, lavar, planchar, todo, y sin embargo ya cuando llega aquí ya no hace nada. Él me dice que cuando llega ya no hace nada porque ya está cansado y enfadado de estar haciendo allá y luego llegar aquí y que siga siendo lo mismo, no, que mejor ya que yo estoy aquí ya se lo haga todo yo. Sólo que por algún motivo yo no pueda, entonces él sí lo haría. 
Estos testimonios dejan entrever que aunque hay cambios en la toma de decisiones, éstos son momentáneos pues al regreso del migrante, éste es quien toma las decisiones y pocas veces se involucra en las actividades domésticas.

Según lo mencionado, cuando estaban en Estados Unidos los hombres realizaban todas sus actividades domésticas, pero una vez que regresaron a Godoy, no volvieron a hacerlas porque ahí estaban sus esposas o madres, quienes estaban precisamente para encargarse de los quehaceres domésticos. Estos argumentos denotan resignación ante esta realidad, pues incluso ellas mismas consideran que esto es algo que no se puede cambiar, y si en algún momento se diera un cambio, éste sería porque así lo dispone el hombre, por su buena voluntad y no por sus propias acciones.

\section{El trabajo doméstico durante la migración}

En Godoy las actividades domésticas las realizan principalmente las jefas o las cónyuges de las unidades (según datos presentados anteriormente), aunque en algunos casos existe apoyo de los demás integrantes. Ese apoyo es brindado principalmente por las hijas mayores de 10 años, y entre más edad tengan las hijas, más ayuda en las actividades domésticas se les exige. Para los hijos la situación es diferente pues no se espera que contribuyan en la realización de las actividades del hogar y se admite con gusto y hasta asombro que los varones ayuden ocasionalmente. Esto muestra una diferenciación en las responsabilidades domésticas que existe entre el trato que se da a las mujeres y a los hombres.

Así, las mujeres son conscientes de que los hombres no ayudan en las actividades del hogar, y en muchos de los casos expresaron su inconformidad por dicha situación y señalaron que los hombres también deben tener responsabilidades en el hogar, aunque por desgracia no llevan a cabo acciones para revertir esa situación. Los esposos se dedican exclusivamente al trabajo asalariado, y una vez terminada su jornada de trabajo se dedican a descansar, ver televisión, salir con los amigos e incluso emborracharse. Sólo en algunos casos excepcionales los esposos ayudan en los quehaceres del hogar.

En los grupos domésticos extensos los familiares agregados, principalmente las nueras y los hijos, contribuyen mínimamente en las actividades 
del hogar, pues se considera que pese a compartir el mismo techo, son una familia aparte. Esta situación es contradictoria pues el nuevo núcleo familiar generalmente sólo cuenta con un cuarto dentro de la casa de los padres del esposo y hace uso de la cocina, sala, baño y todos los demás espacios. Además, siempre hay tensión pues la suegra espera que la nuera realice las actividades que se le asignen, mientras que la nuera busca mecanismos que le permitan evadir dicha responsabilidad-generalmente se justifica con los cuidados de los nietos o nietas.

\section{Reflexiones finales}

Según los resultados expuestos, la migración altera la dinámica habitual de las unidades domésticas y son las mujeres las que asumen las responsabilidades y actividades realizadas por los migrantes (Álvarez, 2005). No obstante, se encontró que existe una diferenciación entre los efectos ocasionados por la migración en las esposas y las madres, pues para las primeras la migración resulta un incremento en sus actividades y responsabilidades, mientras que para las madres la ausencia del hijo trae consigo mayormente problemas de tipo emocional.

El resto de los integrantes del grupo no se vio afectado en sus actividades cotidianas, ya que no asumen las responsabilidades del migrante, tanto los hijos e hijas sólo ayudan ocasionalmente a la madre en alguna tarea. Por otro lado, la migración significa para todas y todos los integrantes un evento que implica grandes cambios emocionales que afectan de manera directa la dinámica de socialización habitual de la unidad doméstica (Suárez y Zapata, 2004).

En Godoy la migración es una estrategia de sobrevivencia que utilizan los grupos domésticos, esto debido a que el papel de proveedor que se le ha asignado al hombre se asume como norma, pues como se vio, las mujeres, ante la ausencia masculina, no desempeñan ninguna actividad asalariada.

La migración masculina en los grupos domésticos con los cuales se trabajó tenía como objetivo principal mejorar la calidad de vida de sus integrantes, esto suponía principalmente un impacto positivo en vivienda, alimentación, vestido, calzado y gastos médicos, y en algunas unidades domésticas se pretendía también tener ahorros. Sin embargo, no en todos los casos se cumplieron dichas metas, pues la mayoría de las remesas se 
utilizaba para los gastos domésticos (alimento, vestido y calzado), lo que provocó que el sentido de la migración no se cumpliera totalmente e intensificó los sentimientos de abandono, tristeza y preocupación por parte de quienes se quedaron en la comunidad.

\section{Bibliografía}

Álvarez R. (2005), “Migración y género", en Instituto Nacional de las Mujeres, Mujeres migrantes y sus implicaciones desde la perspectiva de género, México, Inmujeres.

Alvarado, A. (2004), "Sueños americanos y pesadillas mexicanas. Los cambios en la responsabilidad de las mujeres con los esposos migrantes", en B. Suárez y M. E. Zapata (coords.), Remesas: milagros y mucho más realizan las mujeres indígenas y campesinas, México, Gimtrap.

Ángeles, J., M. Hernández y H. Rosales (1996), "La familia extensa y su importancia en el proceso terapéutico", En G. R. Jiménez (comp.), ¿̇Grupo doméstico, hogar o familia?, México, Universidad Autónoma de Tlaxcala.

Durand, J. (2000), "Tres premisas para entender y explicar la migración MéxicoEstados Unidos", Revista Relaciones, vol. xxi, núm. 83, México, Colegio de Michoacán.

(1991), La migración mexicana a los Estados Unidos. Años veinte: una antología, México, Conaculta.

Gamio, M. (1991), "Número, procedencia y distribución geográfica de los inmigrantes mexicanos en Estados Unidos”, en J. Durand (coord.), La migración mexicana a los Estados Unidos. Años veinte: una antología, México, Conaculta.

Harris, O. (1986), "La unidad doméstica como unidad natural”, Nueva Antropología, vol. viII, núm. 30, México.

Instituto Nacional de Estadística, Geografía e Informática (2005), II Conteo de Población y Vivienda, México, INEGI.

Instituto Nacional de las Mujeres (2005), Mujeres migrantes y sus implicaciones desde la perspectiva de género, México, Inmujeres.

Lacomba, J. (2001), Teorías y prácticas de la inmigración. De los modelos explicativos a los relatos y proyectos migratorios, Barcelona, Scripta Nova 94.

Lomnitz, L. (2006), Cómo sobreviven los marginados, México, Siglo XXI.

Ludger, P. (1997), "Migración laboral internacional y espacios sociales transnacionales: bosquejo teórico-empírico", en M. S. Macías y L. F. Herrera (coords.), Migración laboral internacional, Puebla, BUAP.

Luin, G. (1997), "Difuminando fronteras: construcción de la comunidad transnacional en el proceso migratorio México-Estado Unidos", en M. S. Macías y L. F. Herrera (coords.), Migración laboral internacional, Puebla, BUAP. 
Martínez, C. B. y C. R. Díaz (2005), Metodologías de capacitación de género con mujeres rurales en México, 1990-2003, México, Colegio de Posgraduados, Indesol.

Macías, M. S. (1997), "Migración laboral y movilidad social: método y complementariedad", en S. M. Macías y L. F. Herrera (coords.), Migración laboral internacional, Puebla, BUAP.

Marroni, M. G. (2005), "Soñar por etapas. Mexicanas, frontera y migración a Estados Unidos”, en M. G. Marroni y G. Salgado (coords.), La diáspora latinoamericana: migración en un mundo globalizado, Puebla, BUAP.

Mercado, M. y M. E. Zapata (1995), "Posición de la mujer y estrategias de sobrevivencia ente las transformaciones agrícolas”, en G. R. Jiménez (comp.), ¿Grupo doméstico, hogar o familia?, México, Universidad Autónoma de Tlaxcala.

Oliveira, O. y V. Salles (comps.) (1989), Grupos domésticos y reproducción cotidiana, México, El Colegio de México.

Rojas Soriano, Raúl (2002), Guía para la realización de investigaciones sociales, México, Plaza y Valdés.

Rivermar, M. L. (2002), “Migración y reorganización de las relaciones conyugales y familiares en una comunidad nahua”, en M. G. Marroni y M. E. D’ Aubeterre (coords.), Con voz propia. Mujeres rurales en los noventa, t. I, México, GIMTRAP.

Salles, V. (1991), "Cuando hablamos de familia, ¿̇e qué familia estamos hablando?”, Nueva Antropología, vol. xi, núm. 39.

Suárez, B. y M. E. Zapata (coords.) (2004), Remesas: milagros y mucho más realizan las mujeres indígenas y campesinas, vol. I, México, GIMTRAP.

Artículo recibido el 28 de abril de 2011

Segunda versión recibida el 4 de mayo de 2012

Artículo aprobado el 27 de junio de 2012 